\title{
INVENTORY MODEL USING BAYESIAN DYNAMIC LINEAR MODEL FOR DEMAND FORECASTING
}

\author{
(Modelo de inventarios que utiliza el modelo lineal dinámico bayesiano para el pronóstico de \\ demanda)
}

\author{
Marisol Valencia Cárdenas*, Juan Carlos Correa Morales**, Francisco Javier Díaz Serna***
}

*Facultad de Minas, UNAL. Grupo investigación UNGIDO, mvalencia@unal.edu.co.**Escuela de Estadística, UNAL, Grupo investigación en Estadística, jccorrea@unal.edu.co,*** Facultad de Minas, UNAL. Grupo investigación UNGIDO, javidiaz@unal.edu.co

(Recibido junio 5 de 2014 y aceptado agosto 27 de 2014)

\begin{abstract}
Resumen:
Un factor importante de los procesos de manufactura es la administración de los inventarios de producto terminado. Constantemente la industria está en busca de mejores alternativas para establecer adecuados planes de cantidades por producir y almacenar, a costo óptimo, logrando con ello un horizonte que permita definir con anticipación la logística y los recursos necesarios para la entrega a tiempo de sus productos. La ausencia de datos históricos, requeridos por muchos modelos estadísticos para pronosticar, exige la búsqueda de nuevas técnicas de estimación de demanda con precisión. Este trabajo presenta una alternativa que no solo permite pronosticar de forma ajustada a la realidad, sino dar cantidades óptimas para producir y almacenar inventarios a costo óptimo, usando estadística bayesiana. Se ilustra la propuesta con datos reales.
\end{abstract}

Palabras clave: estadística bayesiana, optimización, modelo de inventarios, modelo lineal dinámico bayesiano.

\section{INTRODUCTION}

Internal logistic in an enterprise has implied the need for good management of its inventories, in special of terminated product. This is often affected by problems that cause uncertainty, like bad forecasts, changes in markets, entry of new firms, producing a very large variability in demand affecting all management processes (Sarimveis et al., 2008; Simchi-Levi et al., 2008).

\begin{abstract}
:
An important factor of manufacturing process is the inventory management of terminated product. Constantly, industry is looking for better alternatives to establish an adequate plan of production and stored quantities, with optimal cost, getting quantities in a time horizon, which permits to define resources and logistics with anticipation, needed to distribute products on time. Total absence of historical data, required by many statistical models to forecast, demands the search for other kind of accurate techniques. This work presents an alternative that not only permits to forecast, in an adjusted way, but also, to provide optimal quantities to produce and store with an optimal cost, using Bayesian statistics. The proposal is illustrated with real data.
\end{abstract}

Keywords: Bayesian statistics, optimization, inventory models, dynamic linear model.

Between the functions of the warehouses of a company are: to keep raw materials and access to this and maintain inventory information for purchases (Silva, 2006; Simchi-Levi et al., 2008). But also to establish a monitoring and control over the production and finished product storage; all this, through appropriate planning policies, which are summarized in a purpose: optimal inventory management (Correa \& Gómez, 2009; SimchiLevi et al., 2008). 
The search for adequate techniques to estimate demand under uncertainty, has become very important to the industry, but also to provide mechanisms to plan production orders, store, and also distribute optimally (Feng et al., 2006; Sarimveis et al., 2008; Sethi et al., 2003; Silva et al., 2008; Silver, 2004). That is the reason why the forecasting models are a tool that permits reduction of that uncertainty, and possible variability problems.

In addition, optimization techniques have been developed to provide a good planning horizon in lower possible time (Gutiérrez \& Vidal, 2008; Sarimveis et al.,
2008). Some of these techniques are based on analytical methods (Gregory, 2010), heuristics and metaheuristics (Feng et al., 2005; Jeyanthi \& Radhakrishnan, 2010; Singh, 2012; Zanakis \& Evans, 1981). Metaheuristic processes are flexible alternatives in order to solve linear and nonlinear problems with many variables, many constrains or both.

In enterprise systems as shown in Figure 1, a lot of information is required for effective planning of the amounts to supply the market with precise forecasts, but also, quantities to be ordered and kept.

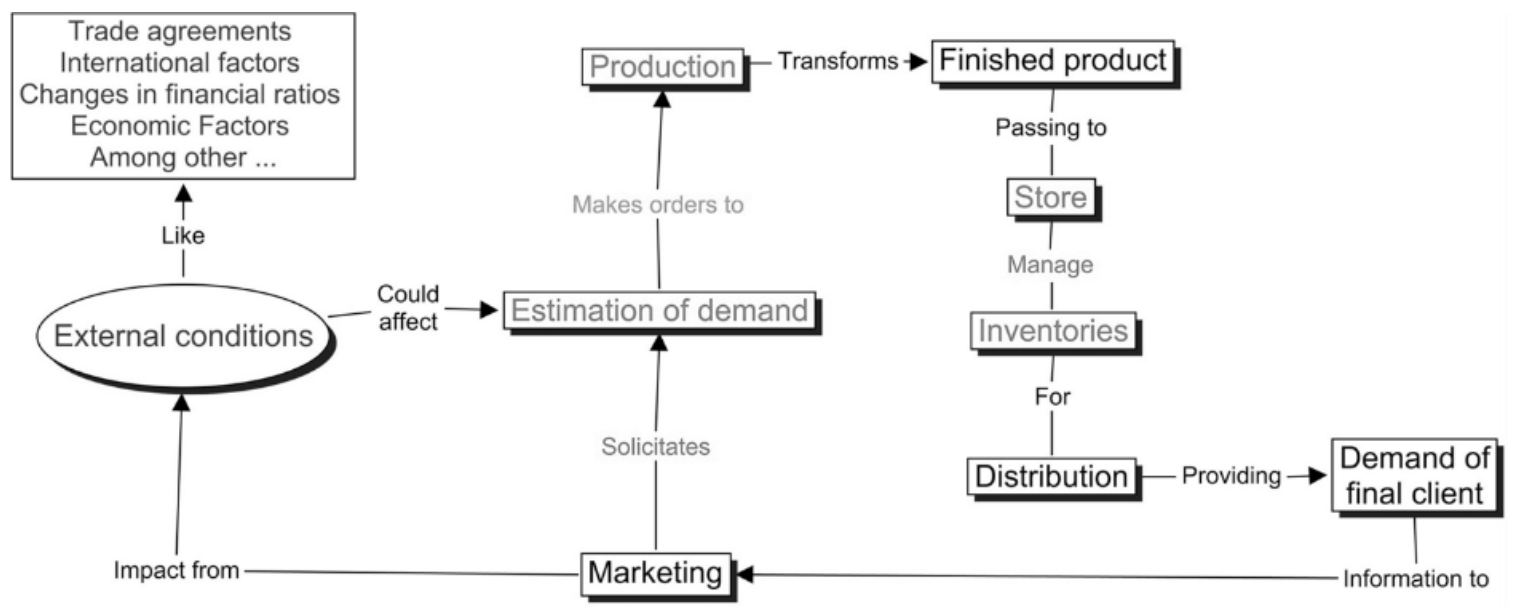

Figure 1. Flow of demand behavior and inventories in a company.

The demand forecast usually requires feedback from end users, so it is necessary to store information on demand to allow an estimate of special techniques of forecasting.

However, some external conditions can affect existing information from the demand (Sarimveis et al., 2008; Simchi-Levi et al., 2008), therefore proper planning is necessary to satisfy the market, providing quantities to produce and store every period to feedback the organization flow continuously.

The theoretical structure of techniques such as time series regression, or even Autoregressive Integrated Moving Average Model (ARIMA), generally must meet certain assumptions, such as: normal Distribution for residuals, constant variance, and uncorrelated residuals (Bowerman et al., 2007; Makridakis et al., 2011; Montgomery et al., 2006). Compliance with these assumptions usually do not always guarantee a predictive success, therefore statistics as Mean Absolute Percentage Error (MAPE), Root of Mean Square Error (RMSE) are used; they can give an idea of the ability to forecast the estimated models.

Recent researches show alternative techniques that do not have the same structures of classical models, like Artificial Neuronal Networks (ANN), which could be accurate with many historical data (Medina \& García, 2005; Rueda, Velásquez \& Franco, 2011). Also, about Bayesian Techniques (Bolstad, 1986; Choi, Li, \& Yan, 2003; Wang, 2006), applicable to forecasting, with few historical data, and provide mechanisms for optimal inventory planning processes. Few works have done this type of process, where the benefits of optimization are used to find an optimal point. Mockus (2002) looks the best among three heuristics: Monte Carlo Heuristic, Linear Randomized Heuristic, ratio of greedy Heuristic, 
inside a global, denominated Bayesian Heuristic Approach (BHA).

On such Bayesian processes, the theoretical assumptions are based on the definition of the posterior distribution of parameter: $\theta: \xi(\theta \mid$ datos $)$. This distribution is proportional to the product of the prior probability $\xi \theta$ and the likelihood: $L($ data $\mid \theta)$. Such Bayesian techniques are applicable even when there is no initial information about q; for example, when using a priori distribution uniform, or some other non-informative distribution (Barrera \& Correa, 2008; Congdon, 2002; Gill, 2007; Harrison \& West, 1991; Martin et al., 2011).

Sometimes, Bayesian estimation processes involve complex theoretical structures difficult to optimize, requiring the use of simulation algorithms based on posterior distributions for the parameters, usually through Monte Carlo Markov Chains (Congdon, 2002).

Some companies do not have extensive data to develop sales forecasts, neither a technique to incorporate this process with inventory optimization. This paper presents a method, using Bayesian statistics in both aspects.

Inventory optimization could also be done with analytical techniques (Feng et al., 2005; Tamura, 1975; Urban \& Baker, 1997), but most of them require the demand as an input. Other techniques are metaheuristics, (Jeyanthi \& Radhakrishnan, 2010; Salpasaranis \& Stylianakis, 2012; Sarimveis et al., 2008; Yang, Chan, \& Kumar, 2012; Yokoyama, 2002), but is difficult to incorporate distributional changes to update statistics of orders, or perform a stochastic sampling, as in this proposal.

This paper presents a unification of a Bayesian Dynamic Linear Model for predicting the demand; for sales defined in a time horizon of 12 months for 2013; with a process of Bayesian Optimization, minimizing inventory costs. These processes will be done by updating the posterior Bayesian distribution, and the predictive one, followed to generate the respective quantities to order, store and estimating shortfalls for all the periods of 2013.

\section{METHODOLOGY}

The forecasting process begins with the estimation of dynamic Bayesian linear model, cycle that is introduced into the Bayesian optimization process on inventories, to finally determine the amounts of demand, ordering and storage, time $t$, with $t=1, \ldots . T$.

Variables, parameters and constants considered here are shown in Table 1.

Table 1. Definition of terms for the models.

\begin{tabular}{|c|c|}
\hline $\begin{array}{l}\text { Parameter } \\
\text { or variable }\end{array}$ & Description \\
\hline$x_{t}$ & $\begin{array}{l}\text { Decision variable. Order in the t-th pe- } \\
\text { riod. }\end{array}$ \\
\hline$D_{t}$ & $\begin{array}{l}\text { Input from Dynamic Linear Model } \\
\text { (DLM). Demand the t-th period. }\end{array}$ \\
\hline$C_{t}$ & $\begin{array}{l}\text { Constant. Unit cost of production for the } \\
\text { t-th period. }\end{array}$ \\
\hline$I_{t}$ & $\begin{array}{l}\text { Output. Final inventory of the } t \text {-th peri- } \\
\text { od. }\end{array}$ \\
\hline$h_{t}$ & $\begin{array}{l}\text { Constant. Unit cost of storing inventory } \\
\text { in the } \mathrm{t} \text {-th period. }\end{array}$ \\
\hline$C f_{t}$ & Constant. Unit cost of shortfall quantities \\
\hline \multirow[t]{2}{*}{$w_{t}$} & Output. Shortfall Quantities. \\
\hline & $\begin{array}{l}\text { As a conditional, if } I_{t}<0 \text {, then } w_{t}=-I_{t} \text {, } \\
\text { else } w_{t}=0\end{array}$ \\
\hline
\end{tabular}

The complete process is summarized in figure 2, explaining cycle of predictions and optimization.

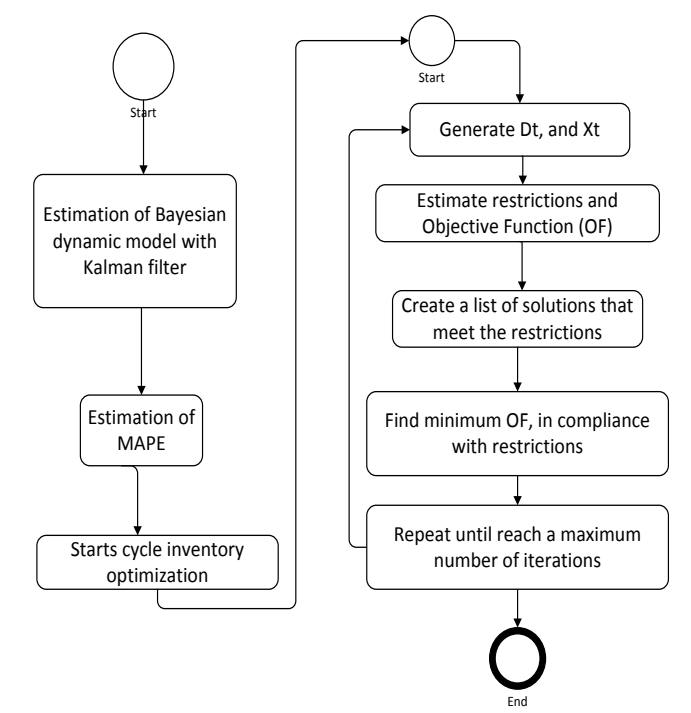

Figure 2. Flowchart of the forecasting and optimization problem. 


\subsection{Bayesian dynamic linear model}

Statistical structure of time series models can be complemented by a dynamic process, which are "changes in such processes due to the passage of time as principal motivator" (West \& Harrison, 1997). In this work we use the Kalman Filter to estimate a Dynamic Linear Model, before doing the Bayesian optimization to find the best possible inventory policy.

Based on Valencia \& Correa (2013) and Meinhold \& Singpurwalla (1983), the next procedure was followed:

$\Rightarrow$ Begin from an initial value of the parameter: $\theta o$

$\Rightarrow$ Generate $\theta_{\mathrm{t}}$ with normal priori distribution with mean: $\mu=G_{t} \hat{\theta}_{t-1}$.

$\Rightarrow$ Estimate mean and variance as:

$$
\begin{gathered}
\hat{\theta}_{t}=G_{t} \hat{\theta}_{t-1}+R_{t} F^{\prime}{ }_{t}\left(V_{t}+F_{t} R_{t} F_{t}^{\prime}\right)^{-1} e_{t}(1) \\
\sum_{t}=R_{t}-R_{t} F^{\prime}{ }_{t}\left(V_{t}+F_{t} R_{t} F^{\prime}{ }^{\prime}\right)^{-1} F_{t} R_{t}(2)
\end{gathered}
$$

$\Rightarrow$ Update the posterior distribution: $\left(\theta_{\mathrm{t}} \mid Y_{t-1}\right) \sim N\left(\hat{\theta}_{t-1}, \sum_{t-1}\right)$, using previous parameters, for the normal posterior distribution to estimate $\theta_{t-1}$

$\Rightarrow$ Estimate system equation:

$\Rightarrow \theta_{t}=G_{t} \theta_{t-1}+w_{t, \text { using estimated value } \theta_{t-1}}$

$\Rightarrow$ Estimate observation equation:

$$
\hat{Y}_{t}=F_{t} G_{t} \hat{\theta}_{t-1}+u_{t}(3)
$$

$\Rightarrow$ Here the equation used was:

$$
\hat{Y}_{p}=G_{t} \hat{\theta}_{t}+0.9 * F_{t} * \mu_{t}(4)
$$

$\Rightarrow$ Predict $\widehat{Y}_{\mathrm{p}}$ using normal predictive distribution, with $\widehat{\mathrm{Y}}_{\mathrm{t}}$ and variance $\mathrm{Rt}$

$\Rightarrow$ Estimate error $\mathrm{e}_{\mathrm{t}}=\mathrm{Y}_{\mathrm{o}}-\widehat{\mathrm{Y}}_{\mathrm{p}}$ and the cycle restarts.

\subsection{Inventory model}

This model will be developed for a single product, but subsequently this could be stated as a multi-level model. The following equation (5) was the first objective function to be optimized, considering the definitions showed at the Table 1:

$$
Z=\sum_{t=1}^{T} C_{t} x_{t}+\sum_{t=1}^{T} h_{t} I_{t}+\sum_{t=1}^{T-3} C f_{t} * w_{t}
$$

The second objective function to be optimized is the expression (6), which represents a quantification of an expected cost, according to the predictive Bayesian distribution of the decision variable $X_{t}$ estimated by the Bayesian process.

$$
Z=\sum_{t=1}^{T} C_{t} E\left[x_{t}\right]+\sum_{t=1}^{T} h_{t} I_{t}+\sum_{t=1}^{T-3} C f_{t} * w_{t}(6)
$$

These equations will be subjected to constraints of the expressions shown in equations (7) to (9)

Ordering constraints

$$
x_{t} \leq \sum_{i=t}^{T} D_{i}
$$

Inventory balance constraints

$$
I_{t}=x_{t}+I_{t-1}-D_{t}
$$

Shortfall constraints

$$
\begin{gathered}
\text { If } I_{t}<0, \text { then: } w_{t}=-\left(I_{t}\right) \text { else: } w_{t}=0 \\
x_{t}, w_{t}, I_{t} \geq 0 \\
\text { For } t=1, \ldots . T
\end{gathered}
$$

The search of the decision variables was made with Bayesian techniques.

For the expressions denoted by (7), we assumed that the order at the $t$-th time can only reach the maximum sum of the demands, from the $t$-th period, until the last one, so every period does not consider the $t-1$ previous periods.

For the expressions denoted by (7), we assumed that we have an initial quantity $I_{0}$ of inventory, and at the following periods, the final inventory was $I_{t}$.

For the expressions denoted by (8), the shortfall quantities were presented by the negative of the inventories, so we will always calculate them at the $t$-th time.

The search of the variable $x_{t}$ is a process done with the Bayesian Statistics technique explained in the next section.

\subsection{Bayesian Optimization}

As it is shown in Table 2, the assumptions of this process were: a Truncated Normal prior distribution for the mean, 
uniformly distributed data, and therefore, the posterior, Truncated Normal, as a product of the previous two.

Table 2. Distribution assumptions

\begin{tabular}{|l|l|}
\hline $\begin{array}{l}\text { Distribution for } \\
\text { Data }\end{array}$ & Uniform $\left(a_{l}, b_{P}\right)$ \\
\hline$\mu$ - priori & Normal Truncated $\left(\mu_{o}, \sigma_{o}^{2}, a, b\right)$ \\
\hline
\end{tabular}

$$
\xi(\mu)=\frac{\frac{1}{\sqrt{2 \pi} \sigma_{o}} e^{-\frac{\left(\mu-\mu_{o}\right)^{2}}{2 \sigma_{o}^{2}}}}{F(b)-F(a)} \alpha e^{-\frac{\left(\mu-\mu_{o}\right)^{2}}{2 \sigma_{o}^{2}}}
$$

It is proportional to the constants, which does not depend on parameters. The product between the Prior Distribution (10) and the Likelihood function will lead to a Posterior Distribution for the mean of the uniform distribution.

\subsection{Posterior}

$$
\begin{array}{r}
\xi\left(\mu, \sigma_{o} \mid \text { datos }\right) \alpha \xi\left(\mu, \sigma_{o}\right) * \frac{n}{b_{1}-a_{1}} \\
\xi\left(\mu, \sigma_{o} \mid \text { datos }\right) \alpha \frac{n}{b_{1}-a_{1}} * \frac{f\left(\mu, \sigma_{0} \mid \text { datos }\right)}{F(b)-F(a)} \alpha \frac{1}{\sigma_{o}} e^{-\frac{\left(\mu-\mu_{o}\right)^{2}}{2 \sigma_{o}^{2}}}
\end{array}
$$

It results to be proportional to the constants, which does not depend on the parameters, and $\sigma o$ is assumed to be constant.

Other side, the predictive distribution is the integral between: uniform distribution of the data, and the posterior NT.

\subsection{Predictive Bayesian distribution}

Predictive distribution (12), as the integral of the data and posterior distribution will be the Uniform. This distribution is used to forecast, after mean update, using the posterior for every time $t$.

$$
\begin{gathered}
P\left(X_{t+1} \mid x\right) \alpha \int_{-\infty}^{\infty} \frac{1}{b_{1}-a_{1}} * \frac{1}{\sigma_{o}} e^{-\frac{\left(\mu-\mu_{o}\right)^{2}}{2 \sigma_{o}^{2}}} d \mu \\
=\frac{\sqrt{2 \pi}}{b_{1}-a_{1}} \\
P\left(X_{t+1} \mid x\right) \alpha \frac{1}{b_{1}-a_{1}}
\end{gathered}
$$

This is a uniform distribution

Decision variables $X_{t}$ were calculated after mean value $\mu_{t}$ is updated with the Posterior Distribution.

\section{ALGORITHM}

1. The procedure performed to optimize the costs of inventories using the $R$ statistical software is as follows:

2. Initialize matrices of orders, inventories and corresponding shortfalls for period $t$ with $t=1 \ldots T$.

3. Generate the decision variable $X$, quantity to order, according to the Bayesian search.

4. Set the search based on a sequence of possibilities $X_{t}$

5. Calculate the final inventories, It, according to the balance equations, given by (7), and the values of these previous demands and orders

6. Set the conditional: if the inventory is negative, change it to zero and shortfall value is the positive of this inventory, so: $w t=-I_{t}$. If it is positive, then $\mathrm{w}_{t}$ is cero.

7. Run for each $j$ from 1 to $M$ sequences and estimate $T$ values of orders and inventories, according to those $M$ quantities.

8. Estimate the $j$-th value of the objective function (OF) given by the expression (5) (or the other case, (6)), keeping each value on a vector.

All decision variables must be positive.

9. Determine the be st solution with minimum cost, estimating the restrictions (7) to (9).

10. $\bar{D}$ is the averag e demand for $T$ periods. If the shortfalls exceed this value, they are penalized, so the quantities in inventory should increase at the same amount. In ventories and final objective function are recalculated.

11. Simulate using the Bayesian predictive distribution 
for orders, until finding the maximum number of restrictions.

One of the advantages of this algorithm designed in $\mathrm{R}$ over the programming software LINGO, is that here we do not need to type demands. In the $\mathrm{R}$ algorithm we can obtain all values at the end, including forecasts and orders, and we also can establish a comparison to determine the efficiency of the designed $\mathrm{R}$ algorithm and the LINGO solution.

\section{INTEGRATION MODELS: FORECASTING AND INVENTORY OPTIMIZATION}

Preliminary results of the Bayesian Dynamic Linear Model (Bayesian DLM) are shown. Then, results and explanations of the optimization model are analyzed.

\subsection{Exploratory results}

Figure 3 shows the real demand versus forecasts for 12 month. It shows in black, real demand quantities, and in red, forecasted values estimated with the Bayesian DLM.

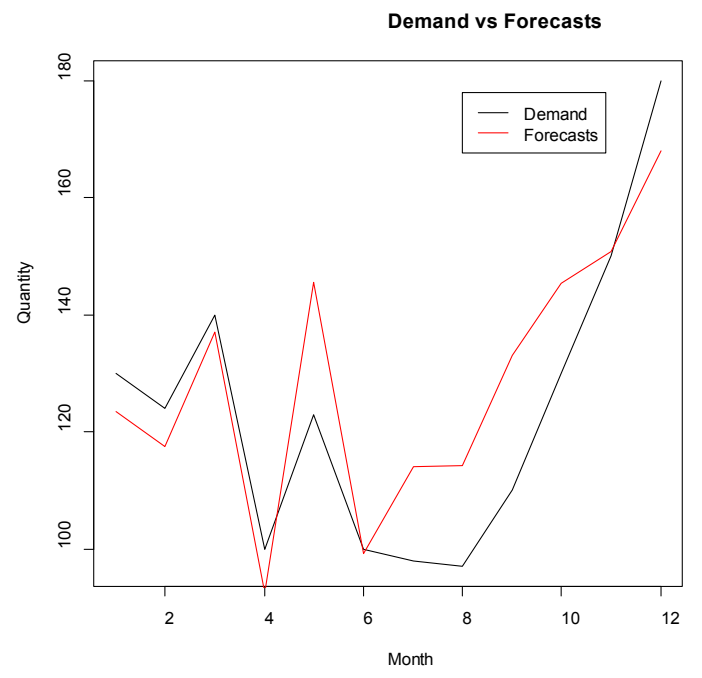

Figure 3. Real versus prediction for demand.

The Bayesian Dynamic Linear Model gives an accuracy in comparison with real data, according to the value found of the MAPE: $9.42 \%$.

4.2 Combining forecasts with inventory optimization.
Initial inventory is $I_{0}=10$. After simulating 1000 iterations, the results of minimum cost were calculated with three scenarios: Percentile 5, median and expected cost of orders.

Table 3. Optimal Results with percentile 5 for the $X_{t}$ variable

\begin{tabular}{lccccc}
\hline Month & $\boldsymbol{X}_{\boldsymbol{t}}$ & $\boldsymbol{I}_{\boldsymbol{t}}$ & $\boldsymbol{D}_{\boldsymbol{t}}$ & Shortfalls & $\begin{array}{c}\text { Costs per } \\
\text { month }\end{array}$ \\
\hline 1 & 116 & 2 & 124 & 0 & 2466 \\
2 & 116 & 0 & 118 & 0 & 2436 \\
3 & 136 & 0 & 136 & 0 & 2856 \\
4 & 92 & 0 & 92 & 0 & 1932 \\
5 & 144 & 0 & 144 & 0 & 3024 \\
6 & 99 & 0 & 99 & 0 & 2079 \\
7 & 114 & 0 & 114 & 0 & 2394 \\
8 & 114 & 0 & 114 & 0 & 2394 \\
9 & 133 & 0 & 133 & 0 & 2793 \\
10 & 145 & 0 & 145 & 0 & 3045 \\
11 & 150 & 0 & 150 & 0 & 3150 \\
12 & 166 & 0 & 166 & 0 & 3486 \\
& & Total & & & 32055 \\
\hline
\end{tabular}

These results here were obtained after 1 minute of computation, but demand $\left(D_{t}\right)$ is also predicted by the same program here designed in this study (Table 3 ).

Comparing with the LINGO solution, this is a very similar result, the cost is 32025 , giving just $0.09 \%$ of error, but it does not left units or shortfalls on inventory. Besides this, the demand in LINGO is not predicted, it is an input.

One of the advantages in the designed algoritm, is that we can predict values, and also, optimize the inventory costs, at the same time; and the inputs of the forecasting process can be modified according to expert knowledge. This is a difference compared to LINGO program.

In Table 4, the expected inventory cost is shown, calculated with equation (5), with the Bayesian optimization. Here the expected value for $X_{t}, E[X]$, was estimated according to the probability predictive distribution. 
Table 4. Inventory Policy found with Expected cost

\begin{tabular}{lccccc}
\hline Month & $\boldsymbol{X}_{\boldsymbol{t}}$ & $\boldsymbol{I}_{\boldsymbol{t}}$ & $\boldsymbol{D}_{\boldsymbol{t}}$ & Shortfalls & $\begin{array}{c}\text { Costs per } \\
\text { month }\end{array}$ \\
\hline 1 & 125 & 12 & 124 & 0 & 2805 \\
2 & 119 & 13 & 118 & 0 & 2694 \\
3 & 136 & 12 & 137 & 0 & 3036 \\
4 & 93 & 12 & 93 & 0 & 2133 \\
5 & 144 & 11 & 146 & 0 & 3189 \\
6 & 99 & 11 & 99 & 0 & 2244 \\
7 & 114 & 10 & 114 & 0 & 2544 \\
8 & 114 & 10 & 114 & 0 & 2544 \\
9 & 131 & 8 & 133 & 0 & 2871 \\
10 & 142 & 5 & 145 & 0 & 3057 \\
11 & 147 & 1 & 151 & 0 & 3102 \\
12 & 167 & 0 & 168 & 0 & 3507 \\
& & Total & & 33726 \\
\hline
\end{tabular}

The difference of the expected cost is just a 5\% far from the original cost, and inventories are not so high. This provides another policy, providing orders that are not restricted to an exact amount of demand, but are close to it, for the Inventory Model proposed.

\section{DISCUSSION}

The uncertainty of the demand can affect decisions about production and inventory optimization. Despite this, it is necessary for the industry to have adequate techniques in order to optimize all the process. An optimization method is not always the strongest when unexpected changes occur in demand, or when it is, in general, very uncertain.

In all cases, uncertainty often affects inventory orders, but it is useful to provide a planning scenario to be prepared to possible abrupt changes on demand values across the time horizon.

The approach shown, provides an alternative method to forecast and to do optimization with Bayesian techniques and, at the same time, using probability distributions, processes that can be modified if it is necessary. It can also use some known information or expert knowledge, in order to have better results if some changes occur.
In this work, three statistics where used to do the Monte Carlo Markov Chain process of the Bayesian technique; it provides to the industry three ways to organize a planning horizon, with demand forecasting and optimum cost of inventories.

\section{Acknowledgment}

To Colciencias, that provided resources for the doctoral scholarship (567) of Marisol Valencia Cárdenas.

\section{REFERENCES}

Barrera, C. \& Correa, J. (2008). Distribución predictiva bayesiana para modelos de pruebas de vida vía MCMC. Revista Colombiana de Estadística, 31(2), 145-155.

Bolstad, W. M. (1986). Harrison-Stevens Forecasting and the Multiprocess Dynamic Linear Model. The American Statistician, 40(2), 129-135.

Bowerman, B., Koehler, A. \& O’Connell, R. (2007). Forecasting, time series, and regression: an applied approach. Pronósticos, series de tiempo y regresión: un enfoque aplicado. México, DF:. Cencage Learning.

Choi, T.-M., Li, D. \& Yan, H. (2003). Optimal two-stage ordering policy with Bayesian information updating. Journal of the Operational Research Society, 54(8), 846-859. doi:10.1057/palgrave. jors. 2601584

Congdon, P. (2002). Bayesian statistical modelling. London, England: Wiley Series in Probability and Statistics.

Correa, A. \& Gómez, R. (2009). Tecnologías de la información en la cadena de suministro. DYNA, 76(157), 37-48. Retrieved from http://books. google.com/books?hl= en\&l r=\&id=5gbDeVqJPB8C\&oi $=$ fnd \&pg $=$ PA437\&dq $=$ INFORMATION + TECHNOLOGIES + IN + SUPPLY + $\mathrm{CHAIN}+\mathrm{MANAGEMENT \&}$ ots $=$ SI1eiB3r$\mathrm{VP} \& \operatorname{sig}=$ 27QLdpkYqUHVOIJTWEL527kqc_4 
Feng, Q., Gallego, G., Sethi, S., Yan, H. \& Zhang, H. (2005). Periodic-review inventory model with three consecutive delivery modes and forecast updates. Journal of Optimization Theory and Applications, 124, 137-155.

Feng, Q., Sethi, S., Yan, H. \& Zhang, H. (2006). Are base-stock policies optimal in inventory problems with multiple delivery modes? Operations Research, 54(4), 801-807. Retrieved from http:// or.journal.informs.org/content/54/4/801.short

Gill, J. (2007). Bayesian methods: a social and behavioral sciences approach. United States of America: Chapman \& Hall.

Gregory, A. (2010). Revenue and inventory optimization: the necessary evolution of revenue management. The Journal of Hospitality Financial Management, 18(2), 61-63. doi:10.1080/10913 211.2010.10653895

Gutiérrez, V. \& Vidal, C. J. (2008). Modelos de gestión de inventarios en cadenas de abastecimiento: Revisión de la literatura. Revista Facultad de Ingeniería, $N^{\circ} 43,134-149$.

Harrison, J. \& West, M. (1991). Dynamic linear model diagnostics. Biometrika Trust, 78(4), 797-808.

Jeyanthi, N. \& Radhakrishnan, P. (2010). Optimizing multi product inventory using genetic algorithm for efficient supply chain management involving lead time. International Journal of Computer, 10(5), 231-239.

Makridakis, S., Hibon, M., Moser, C., Journal, S., Statistical, R. \& Series, S. (2011). Accuracy of forecasting: an empirical investigation. Journal of the Royal Statistical Society, 142(2), 97-145.

Martin, A., Quinn, K. \& Park, J. H. (2011). MCMCpack: Markov Chain Monte Carlo in R. Journal of Statistical Software, 42(9), 1-21.

Medina, S. \& García, J. (2005). Predicción de demanda de energía en Colombia mediante un sistema de inferencia difuso neuronal. Energética, 33, 15-24.
Meinhold, R. J. \& Singpurwalla, N. D. (1983). Understanding the Kalman Filter. The American Statistician, 37(2), 123-127.

Mockus, J. (2002). Bayesian heuristic approach to scheduling. Informatica, Lith. Acad. Sci., 13(3), 311-332.

Montgomery, D., Peck, E. \& Vining, G. (2006). Introducción al análisis de regresión lineal. Compañia Editorial Continental, 3, 612.

Rueda, V., Velásquez, J. D. \& Franco, C. (2011). Avances recientes en la predicción de la demanda de electricidad usando modelos no lineales. DYNA, 78(167), 36-43.

Salpasaranis, K. \& Stylianakis, V. (2012). A hybrid genetic programming method in optimization and forecasting: a case study of the broadband penetration in OECD countries. $A d-$ vances in Operations Research, 2012, 1-32. doi:10.1155/2012/904797

Sarimveis, H., Patrinos, P., Tarantilis, C. D. \& Kiranoudis, C. T. (2008). Dynamic modeling and control of supply chain systems: A review. Computers \& Operations Research, 35(11), 3530-3561. doi:10.1016/j.cor.2007.01.017

Sethi, S., Yan, H. \& Zhang, H. (2003). Inventory models with fixed costs, forecast updates, and two delivery modes. Operations Research, 51(2), 321-328. Retrieved from http://or.journal.informs.org/content/51/2/321.short

Silva, A.N. (2006). Logística de almacenamiento, Tecana American University Education, Caracas.

Silva, V., Fleming, P., Sugimoto, J. \& Yokoyama, R. (2008). Multiobjective optimization using variable complexity modelling for control system design. Applied Soft Computing, 8(1), 392-401. doi:10.1016/j.asoc.2007.02.004

Silver, E. (2004). An overview of heuristic solution methods. Journal of the Operational Research Society, 55(9), 936-956. doi:10.1057/palgrave. jors. 2601758 
Simchi-Levi, D., Kaminsky, P., \& Simchi-Levi, E. (2004). Managing the supply chain: the definitive guide for the business professional. United States. McGraw-Hill.

Singh, A. (2012). An overview of the optimization modelling applications. Journal of Hydrology, 466-467, 167-182. doi:10.1016/j.jhydrol.2012.08.004

Tamura, H. (1975). Decentralized optimization for distributed-lag models of discrete systems. Automatica, 11, 593-6112.

Urban, T. L. \& Baker, R. C. (1997). Optimal ordering and pricing policies in a single-period environment with multivariate demand and markdowns. European Journal of Operational Research, 103, 573-583.

Valencia, M. \& Correa, J. (2013). Un modelo dinámico bayesiano para pronóstico de energía diaria. Revista Ingeniería Industrial, 12(2), 7-17.

Wang, S. (2006). Exponential smoothing for forecasting and Bayesian validation of computer models.
Doctoral Thesis. Georgia. United-States. Georgia Institute of Technology. In: https://smartech.gatech.edu/bitstream/handle/1853/19753/ wang_shuchun_200612_phd.pdf

West, M. \& Harrison, J. (1997). Bayesian Forecasting and Dynamic Models (Vol 18., p. 704). New York. Springer Series in Statistics. ISBN: 0387947256

Yang, W., Chan, F. T. S. \& Kumar, V. (2012). Optimizing replenishment polices using genetic algorithm for single-warehouse multi-retailer system. Expert Systems with Applications, 39(3), 30813086. doi:10.1016/j.eswa.2011.08.171

Yokoyama, M. (2002). Integrated optimization of inventory-distribution systems by random local search and a genetic algorithm. Computers \& Industrial Engineering, 42(2-4), 175-188. doi:10.1016/S0360-8352(02)00023-2

Zanakis, S. H. \& Evans, J. R. (1981). Heuristic "Optimization": Why, When, and How to Use It. Interfaces, 11(5), 84-91. doi:10.1287/inte.11.5.84 